\title{
Pedagogías maternales: educación y control en la Argentina del siglo XX
}

\section{Maternidad y tecnologías de género.}

DARRÉ, Silvana.

Buenos Aires: Katz Editores, 2013. 226 p.

En las últimas cuatro décadas, las investigaciones sobre la maternidad han ido cobrando importancia dentro del ámbito de las ciencias sociales. Como fenómeno central en la vida de los seres humanos ha ocupado un lugar primordial en las reflexiones de varias disciplinas. En muchas ocasiones el interés en esta temática se ha concretizado en indicaciones, sugerencias $y$ buenas prácticas sobre el mejor desempeño de los roles maternos, llegando incluso a ser mandatos y ordenes muy bien delimitadas.

El último libro de Silvana Darré, coordinadora del Programa Género y Cultura de FLACSO Uruguay y profesora de la misma universidad, se fundamenta en la labor llevada a cabo durante su etapa predoctoral en Ciencias Sociales de FLACSO Argentina. El texto describe e interpreta los discursos producidos en Argentina entre 1920 y 1980 , para educar a las madres. La autora inicia este recorrido preguntándose acerca de cuándo y por qué la maternidad se convirtió en un asunto que requería de conocimientos y aptitudes específicas.

La profesora Darré presenta el proceso de unas transformaciones no lineales de los discursos colectivos procedentes de un amplio abanico de fuentes de la sociedad civil, tales como asociaciones de beneficencia, médicos, psicólogos y psiquiatras que promueven intervenciones morales y pedagógicas que buscan configurar una manera de entender la maternidad y de institucionalizar unas pautas de conducta.

Gracias al análisis de casos concretos, es posible comprobar cómo cada uno de ellos encarna una propuesta pedagógica de maternidad que implica siempre un juicio de valor neto, es decir una separación inconciliable entre lo correcto y lo incorrecto. Al respecto, la autora utiliza la categoría 'maternidad inapropiada' para designar el conjunto de prácticas maternales que se ubican del lado de lo equivocado. Así, a lo largo del texto es posible entender que lo apropiado y lo inapropiado en las madres son términos que se construyen según el momento histórico, a la vez que se naturalizan desde ámbitos profesionales determinados.

La metodología empleada adopta el enfoque arqueológico, fundado en la descripción de los diferentes desplazamientos que ha tenido la idea de 'inapropiado' referido a la maternidad, a la vez que hace hincapié tanto en sus rupturas como en sus continuidades, evidenciando su construcción histórica. En un primer periodo se estudian las instituciones Los Premios a la Virtud y la Escuela de Madres; mientras que para el período entre 1950 y 1980 , se pone atención a los consejos de Florencio Escardó, la Escuela de Padres creada por Eva Giberti y la Asociación Interdisciplinaria para el Estudio y la Prevención del Filicidio - FILIUM - fundada por Arnaldo Rascovsky. Sobre estos casos de estudio se realiza un análisis a tres niveles: 1) las prácticas sociales, que en este caso se trata de pedagogías maternales; 2) las teorías y los principios disciplinarios que justifican tales prácticas; $y, 3$ ) el proceso histórico de la construcción de la categoría de lo 'inapropiado'.

Las pedagogías maternales, valiéndose de los aportes teóricos de Foucault, se entienden como una serie de dispositivos utilizados para educar a unas madres que no cumplen con el rol socialmente esperado. A través de discursos escolares y médicos, se construyen proyectos disciplinarios de control de las vidas de las mujeres, con especial énfasis en las que pertenecen a las clases bajas. Así pues, estas instituciones dejan de proveer consejos para ser 
aparatos reguladores que pretenden una transformación de las mujeres.

Los Premios a la Virtud (1923-1940), creados por Bernardino Rivadavia, se proponían reconocer valores morales en las mujeres de escasos recursos. La dinámica consistía en que las damas de alta sociedad, que encarnaban el modelo de feminidad y maternidad apropiada, se encargaban de entregar los premios a madres que a pesar de origen humilde fueran capaces de alejarse de un destino de miseria, vicio y enfermedad. Bajo esta lógica, las premiadas se destacan por sus conductas 'apropiadas', a la vez que reafirman la existencia de las conductas inapropiada de las otras madres de su mismo estrato social.

La segunda institución es la Escuela de Madres (1920-1955), perteneciente al Patronato de la Infancia. En esta institución la medicina se convierte en una disciplina interventora de las maternidades. La importancia que alcanza la lactancia materna como sinónimo de 'buena madre' es un ejemplo de esta pedagogía. Para este dispositivo, la protección de la infancia se traduce en programas educativos intensos dirigidos a las madres pobres, solteras e inmigrantes, que deben pasar por una reclusión de tres meses en los centros para poder transformar sus comportamientos. Encierro y vigilancia, aunadas a una doctrina higienista, hacen que la Escuela sea en sí misma un programa de re-educación en la crianza infantil. Como bien señala la autora, la Escuela es un ejemplo de ortopedia moral en tanto se propone corregir supuestas anomalías sociales; además, enmarcada dentro del discurso eugenésico, busca la producción de ciudadanos fuertes y sanos, a través de un proceso formativo y selectivo.

Llegando al período 1950-1980, la obra se centra en tres dispositivos: los consejos de Florencio Escardó, la Escuela de Padres y FILIUM. A través de un intercambio constante entre los avances producidos en Europa y Estados Unidos y la literatura latinoamericana, se van configurando estos tres proyectos pedagógicos a la luz de la disciplina 'psi'. La psiquis ocupa un lugar fundamental en la formación del ser humano, por ello la mejor garantía para una infancia óptima es una maternidad apropiada. Los discursos se inclinan hacia las madres y sus relaciones filiales; y los afectos y los cuidados maternales son los ingredientes primordiales para el buen desarrollo infantil.

Poniendo atención a la trayectoria de Escardó, es posible visualizar el cambio conceptual y sustancial de los discursos en torno a la crianza infantil durante los años de 1950 a 1980. Esta metamorfosis se debe a la emergencia del psiquismo en los problemas personales, familiares y sociales. Por ejemplo, en los textos de este autor, es posible ver el paso de una puericultura de corte más tradicional centrada en los cuidados de los niños, hacia una puericultura basada en una pedagogía hacia la familia y en la que los afectos son el centro del proyecto educativo y relacional.

Por su parte, la Escuela de Padres (1957. 1973) y FILIUM (1971-1980) configuran unas pedagogías maternales que a través de los medios de comunicación les permiten alcanzar miles de hogares argentinos. Las dos iniciativas se difunden por medio de publicaciones periódicas programas de radio y televisión, conferencias masivas, cursos universitarios, grupos de estudio y de docentes y escuelas de cuidados. Gracias al señalamiento de que los primeros cinco años de vida son fundamentales para el futuro de los niños y las niñas, los dos dispositivos centran sus acciones en los periodos previos a la concepción, al embarazo y a la primera infancia. Para la Escuela de Padres, el objetivo principal es lograr la felicidad de los niños, mientras que FILIUM pretende detectar y evitar el filicidio o sus sustitutos simbólicos (abandono y maltrato). Para ambas iniciativas, la posibilidad de ser una madre inadecuada está latente. Es entonces que lo inapropiado se vuelve fácil de alcanzar y se extiende a casi cualquier actitud: desde tener vómitos durante el embarazo, hasta expresar cansancio laboral frente a los hijos, o no recordar sus cumpleaños.

Cada uno de los casos analizados de manera densa y profunda a lo largo del libro es útil para entender el significado de las pedagogías maternales en tanto tecnologías de género, que producen modos de ser madre, a la vez que construyen identidades concretas. No cabe duda que las prácticas sociales estudiadas no son formas de intervención sobre una maternidad inapropiada pre-existente, se trata más bien de un proceso de producción de maternidades adecuadas o inadecuadas, y de propuestas de corrección a través de prácticas pedagógicas.

Si bien en los primeros años las madres incorrectas eran mujeres pobres, inmigrantes o solteras, en el siguiente período de estudio, el grupo intervenido es otro. Este cambio pone en evidencia el carácter histórico y cultural de los dispositivos pedagógicos estudiados, porque se evidencia cómo cada uno responde a una serie de referencias que atañen lo deseable en términos teóricos, disciplinarios y, por tanto, 
también políticos y sociales de cada etapa del recorrido histórico en examen.

Como bien señala Silvana Darré en las conclusiones, los casos elegidos para la investigación no agotan el análisis de las tecnologías de género que configuran un modelo de maternidad deseado y exigido. Esta obra pionera alienta a seguir en la búsqueda de evidencias que permitan entender cómo esa maternidad tan naturalizada es el resultado de recursos discursivos y de iniciativas articuladas que estructuran significados y valoraciones sobre lo que se considera apropiado o inapropiado. En ese sentido, lejos de cerrar los debates en torno a la construcción sociocultural de la maternidad, este libro abre nuevas interrogantes y nuevas líneas de investigación, ya sea en Argentina, como en otros países y contextos socio-culturales más o menos amplios. Al respecto, estudiar en clave de pedagogías maternales las relaciones que se dan entre el poder y el saber puede ayudar en el entendimiento, por ejemplo, de las prácticas de robo de niños de parte del Estado, tal como ha sido evidenciado en Argentina, o los cambios legislativos del código penal en temas relacionados al filicidio o el maltrato infantil a nivel internacional. Asimismo, resultaría innovador registrar las propias experiencias de las madres concretas que se mueven entre lo apropiado y lo inapropiado, as como sus prácticas de resistencia al modelo hegemónico, para desarticular la naturalidad con la que se concibe el amor, los afectos y las relaciones materno-filiales, recuperando los matices de las vivencias $y$, principalmente, la complejidad que atañe a la maternidad, que en estas dicotomías tan intransigentes queda reprimida y limitada.

Ana Lucía Hernández Cordero Universidad Autónoma de Madrid 